Diese Ergebnisse erlauben den Schluß, daß Zusatz von Glukose die Verbrennung von Aminosäuren, die zumindest teilweise das endogene Substrat darstellen, hemmt, d.h. anders ausgedrückt, eine Einsparung des zelleigenen Aminosäurebestandes bewirkt. Unter diesen Umständen beobachteten wir bei Retikulozyten Hämoglobinsynthese ${ }^{5}$ ). Es finde offensichtlich eine Verdrängung endogener Substrate durch Glukose statt, deren Mechanismus weiterer Untersuchungen bedarf. Als Erklärung für die Herabsetzung der Sauerstoffaufnahme sind verschiedene Möglichkeiten in Betracht zu ziehen. Wir möchten insbesondere auf die Tatsache hinweisen, da.B bei Zusatz von Glukose aerobe Glykolyse auftritt, die bei Asciteszellen die Hälfte des Energiebedarfs der Zellen zu decken imstande ist ${ }^{6}$. Somit wäre in Gegenwart von Glukose bei gleichem Energiebedarf eine kleinere Sauerstoffaufnahme als unter endogenen Bedingungen zu erwarten. Daraus ist zu folgern, daß die Glukosehemmung der Atmung um so stärker auftritt, je größer die aerobe Glykolyse ist [s, auch ${ }^{4}$ )]; damit ließe sich die Größe des Effektes bei Tumorzellen zwanglos erklären. Schließlich muß noch betont werden, daß der häufig verwendete Ausdruck ,umgekehrter Pasteur-Effekt" für die Glukose-Hemmung der Atmung nur im Hinblick auf den Anteil der aeroben Glykolyse an dem Energiebedarf der Zelle zutrifft. Andererseits besteht der wesentliche Unterschied darin, daß der Pasteur-Effekt die Beziehung zwischen aerobem und anaerobem Stoffwechsel eines Substrats betrifft, während es sich bei dem diskutierten Effekt um die Beziehung zwischen verschiedenen Substraten unter aeroben Bedingungen handelt

Wir danken Herrn Professor Dr. E. Negelein (Deutsch Akademie der Wissenschaften, Institut für Medizin und Biologie) für die freundliche Überlassung der Tumormäuse.

Physiologisch-Chemisches Institut der Humboldt-Universität, Berlin

S. RapoporT, H.G. SchWEigER and H. BrandT

Eingegangen am 15. Oktober 1957

1) Warburg, O., F. Kubowitz u. W. Christian: Biochem. $Z$ 242, 170 (1931). - 2) Warburg, O., K. Posener 11. E. Negelern: Biochem. Z. 152, 309 (1924). - 3) CRABTREE, H.G.: Biochemic. J. 23, 536 (1929). - 4) Luganova, J.S., J.F. SEItZ u. W.J. THEODoRowrtch: Dokl. Akad. Nauk SSSR. 112, $1082(1957) .{ }^{5}$ ) SchWEIGer, H.G., S. Rapoport u. E. Schölzel: Hoppe-Seylers Z. physiol. Chem. 306, 33 (1956). - ${ }^{6}$ ) WARBURG, O.: Naturwiss, 42, 401 (1955)

\section{Über Stoffwechselvorgänge im Fremdkörpergranulationsgewebe}

Werden Fremdkörper, wie Kunststoffe, Siliciumdioxydderivate, Eiweißstoffe oder Ester hochungesättigter Fettsäuren in die Subcutis von Mäusen und Ratten implantiert, so lassen sich in den Zellen der dabei entstehenden Fremdkörpergranulome mit histochemischen Methoden ${ }^{1}$ ) eine Reihe von Enzymen nachweisen:

Die mononucleären Phagozyten und die Fremdkörperriesenzellen besitzen in allen Granulomen eine sehr starke Aktivität von saurer Phosphatase, Phosphoamidase, $\beta$-Glucuronidase und Aminopeptidase. Außerdem läßt sich bei der Verwendung von $\alpha$-Naphthylacetat als Substrat häufig im Zytoplasma der Riesenzellen eine Esteraseaktivität nachweisen. Alkalische Phosphatase, 5-Nucleotidase, Dehydrogenasen, Oxydasen und Peroxydasen konnten in den phagozytierenden Zellen mit histochemischen Methoden nicht festgestellt werden.

Die Fibroblasten in der bindegewebigen Kapsel der Granulome zeigen bei der Verwendung von Naphthol-AS-Acetat als Substrat eine deutliche Esteraseaktivität. Weiterhin besitzen diese Zellen eine schwache Aktivität von Aminopeptidase und $\beta$-Glucuronidase sowie gelegentlich auch von saurer Phosphatase und Phosphoamidase. - Die Kapillavwände am Rand der Granulome sind durch ihre starke Aktivität von alkalischer Phosphatase ausgezeichnet. Die neu gebildeten Kapillarsprossen im Innern der Granulome besitzen demgegenüber noch keine Phosphataseaktivität. Gelegentlich zeigen die Kapillarwände auch eine schwache $\beta$-Glucuronidaseund Aminopeptidaseaktivität. - Die polymorphkernigen Levkozyten geben deutliche Oxydase- und Peroxydasereak tionen. Innerhalb der Gefäße enthalten die Leukozyten ferner eine Aktivität von alkalischer Phosphatase, während die in das Gewebe emigrierten Leukozyten keine Phosphataseaktivität besitzen. - In den ruhenden, inaktiven Bindegewebszellen (Histiozyten) in der weiteren Umgebung der Granulome findet sich keine nennenswerte histochemisch nachweisbare Enzymaktivität.

Bei allen Versuchen trat die Enzymaktivität in den Phagozyten schon 3 bis 7 Tage nach der Implantation der
Fremdkörper auf und blieb über lange Zeit ( 1 bis $1^{1 /}$ Jahre) nahezu konstant. Erst beim Übergang alter Granulome in ein faserreiches Narbengewebe verschwand die Aktivität der hydrolytischen Fermente allmählich.

Die Verteilung und Aktivität der Enzyme war in den verschiedenen Granulomen gleichartig und unabhängig von der Art der verabfolgten Fremdkörper. Hinweise anf eine adaptive, durch die chemische Beschaffenheit der Fremdkörper induzierte Aktivierung (oder Bildung) von Enzymen fanden sich nicht. Die Frage, ob in den phagozytierenden Zellen Fermente aktiviert oder synthetisiert werden, läBt sich an Hand histochemischer Untersuchungen nicht sicher ent scheiden. Wenn man jedoch berücksichtigt, daß der Enzymstoffwechsel der Zellen lebhaft ist und in seiner Intensität den der Strukturproteine und anderer Eiweißstoffe bei weitem übertrifft (LANG) ${ }^{2}$ ), so dürfte die Annahme naheliegend sein, daß in den Phagozyten neben einer Aktivierung auch eine Synthese von Enzymen stattfindet.

Die Enzymausrüstung der histiocytären Zellelemente ist also erheblichen Schwankungen unterworfen. Sie besitzen im Ruhezustand nur einen geringen Fermentgehalt, der bei funktionellen Leistungen (z. B. Phagozytose) gesteigert wird. Offenbar werden die Artivität und die Synthese der Fermente in wesentlichem Umfang durch die funktionelle Beanspruchung dieser Zellen und damit von inren Stoffwechselleistungen bestimmt.

Die weitgehende Übereinstimmung der Fermentausrüstung der Fremdkörperriesenzellen mit den enzymatischen Leistungen der mononucleären Phagozyten bestätigt die durch morphologische Beobachtungen begründete Auffassung, daß die Riesenzellen aus den zur Phagozytose befähigten histiocytären Zellen entstehen. Ihre Enzymausstattung weist ferner darauf hin, daß sie erhebliche Stoffwechselleistungen vollbringen und nicht von vornherein funktionell minderwertige Zellen darstellen.

In den Riesenzellen vom Langhans-Typ wurde gelegentlich eine unterschiedliche Verteilung der Fermentaktivität beobachtet. Meistens war zwar die Aktivität der hydrolytischen Enzyme in den Riesenzellen mit randständigen Kernen genau wie in den üblichen Fremdkörperriesenzellen - in der Peripherie und im Zentrum gleich stark ausgeprägt oder sogar in den zentralen Bezirken etwas deutlicher als in den peripheren. Daneben fanden sich aber nicht selten Riesenzellen, deren Fermentaktivität ausschließlich auf die kernhaltige, basophile Zellperipherie beschränkt war, während die zentralen Bezirke keine histochemisch nachweisbaren Enzyme besaßen. Dieser Befund steht mit der Annahme im Einklang, daß im Zentrum dieser Riesenzellen ein inertes (nekrobiotisches) Material liegt, das nicht mehr im wesentlichen Umfang am Stoffwechsel teilnimmt, und daß nur die kernhaltige Zell peripherie aus lebendem Zytoplasma besteht (LINZBACH) ${ }^{3}$ ).

Die Untersuchungen wurden mit Unterstützung der Deutschen Forschungsgemeinschaft durchgeführt. Die ausführliche Veröffentlichung der Versuchsergebnisse erfolgt in Virchows Archiv.

Pathologisches Institut der Universität, Bonn (Direktor: Prof. Dr. H. HAMPERL)

Peter Gedigk und Erika Bontke

Eingegangen am 4. November 1957

1) Die Reaktionen zum histochemischen Nachweis von Enzymen wurden nach den Arbeitsvorschriften von A. G. E. PEARSE, Histochemistry, Theoretical and Applied, London 1953, und G. GomorI Microscopical Histochemistry, University of Chicago Press, 1953, durchgefuhrt. Einzelheiten der Methodik und der durchgeführten Kontrollversuche sind außerdem in einer früheren Mitteilung be handelt worden von GeDiGk, P., u. E. Bontke: Z. Zellforsch. 44 495 (1956). - $\left.{ }^{2}\right)$ LANG, K.: Die Biologie der Enzyme. In 4. Colloquium der Ges. für physiologische Chemie, S. 1-25. BerlinGöttingen-Heidelberg: Springer 1953. - a) LinzBACH, A. J.: Quantitative Biologie und Morphologie des Wachstums einschlieB. lich Hypertrophie und Riesenzellen. In: Handbuch det allgemeinen Pathologie, Bd. VI/1, S. 254-280. 1955.

\section{The Effect of Succinate and Malonate on the Chemical Release of Histamine from Guinea-Pig Lung Slices}

While there are many analogies between the anaphylactic shock and the one induced by chemical releasers of histamine, some experiments led to admit that a different mechanism underlies both phenomena, as shown recently by MONGAR and SCHILD ${ }^{1}$ ); they could demonstrate, by the use of minced guinea-pig lung, that iodoacetate reduces the histamine release in anaphylaxis and enhances it by 48/80. Recently 